1 Pontifícia Universidade Católica de São Paulo (PUC-SP).

Professor na Faculdade de Direito e foi Chefe de Gabinete na PUC-SP. Foi Pró-Reitor de Pós-Graduação, Pesquisa e Extensão, Coordenador do Mestrado em Direito e professor no UNIVEM. Possui Doutorado em Filosofia do Direito pela PUC-SP. Pós-Doutorado pela Universidade La Sapienza, Roma. Advogado. Líder do Grupo de Pesquisa GEDs - Direitos Fundamentais à Luz da Doutrina Social - PUC-SP. Membro do Conselho Editorial da Revista DD\&EM da Faculdade de Direito da PUC-SP, da Revista de Direito Brasileira - RDBras, do CONPEDI, da Editora Letras Jurídica e Editora Instituto Memória. Avaliador para cursos de direito INEP/MEC. Membro fundador da UJUCASP.

E-mail: lafayette.pozzoli@gmail.com Orcid: https://orcid.org/0000-0001-7512-7549

2 Universidade de Marília (Unimar)

Doutorando no Programa de Doutorado em Direito da Universidade de Marília - Unimar (2020-atual). Membro honorário de E-Justicia Latinoamérica (2013). Membro Efetivo da Associação Brasileira de Direito Processual Constitucional (2020). Membro do Comitê Editorial da Sapientia \& Iustitia - Revista virtual de la Facultad de Derecho y Ciencias Políticas de la Universidad Católica Sedes Sapientiae - UCSS (Peru). Membro do Conselho Consultivo da Revista IusTech Revista de Derecho \& Tecnología - IUSTECH (Peru). Cidadão honorário do Município de Jacarezinho (2021)

E-mail: rogeriocangussu@gmail.com

Orcid:

https://orcid.org/0000-0002-5125-9018

3 Universidade Federal do Pará (UFPA)

Doutorando em direito pela Universidade Federal do Pará (UFPA). Mestre em Direito pelo Centro Universitário Eurípides de Marília UNIVEM.

E-mail:

gilmarsiqueira126@gmail.com

Orcid:

https://orcid.org/0000-0002-0042-4984

\section{EDUCAÇÃO E FRATERNIDADE PARA A PROMOÇÃO DO BEM COMUM}

\author{
EDUCATION AND FRATERNITY FOR THE PROMOTION OF THE \\ COMMON GOOD
}

\author{
Lafayette Pozzoli ${ }^{1}$ \\ Rogério Cangussu Dantas Cachichi ${ }^{2}$ \\ Gilmar Siqueira ${ }^{3}$
}

Como citar: POZZOLI, Lafayette; CACHICHI, Rogério Cangussu Dantas; SIQUEIRA, Gilmar. Educação e fraternidade para a promoção do bem comum. Revista do Instituto de Direito Constitucional e Cidadania - IDCC, Londrina, v. 6, n. 1, e026, jan/jun, 2021. ISSN: 2596-0075. DOI: 10.48159/revistadoidcc.v6n1.e026

Resumo: O objetivo deste artigo é investigar como a educação para o pleno desenvolvimento da pessoa humana envolve a aceitação - ou reabsorção - da circunstância como fundamental para a maturidade da vida. A educação para o desenvolvimento da pessoa abrange seu projeto vital, a dignidade humana e, por essa razão, se verá como ela precisa tender para a liberdade interior a fim de que possa se desdobrar, em seguida, no relacionamento comunitário. Um elemento importante para a educação é também a fraternidade, que será vista na segunda seção do artigo. Seu papel na educação é o de estimular a pessoa na busca pelo bem comum. A pesquisa foi desenvolvida utilizando o método de abordagem hipotético-dedutivo, o procedimento comparativo, a técnica de documentação indireta, a pesquisa bibliográfica: em livros e periódicos jurídicos; documental; em legislação e em sites eletrônicos.

Palavras-chave: educação; direito; fraternidade; bem comum; dignidade humana.

Abstract: The purpose of this article is to investigate how education for the full development of the human person involves the acceptance - or reabsorption - of the circumstance as fundamental to the maturity of life. Education for the development of the person covers his vital project, human dignity and, for that reason, it will be seen how the education needs to tend towards inner freedom so that he can unfold, then, in the community relationship. An important element for education is fraternity, which will be seen in the second section of the article. Its role in education is to stimulate the person in the search for the common good. The research was developed using the hypothetical-deductive approach method, the comparative procedure, the indirect documentation technique, the bibliographic research: in books and legal journals; documentary; legislation and on electronic websites.

Keywords: education; law; fraternity; common good; human dignity. 


\section{INTRODUÇÃo}

Este artigo procurará mostrar como a educação para o pleno desenvolvimento da pessoa humana envolve a aceitação - ou reabsorção - da circunstância como fundamental para a maturidade da vida. A pessoa precisa ter consciência de sua própria história para que passe também a conhecer seu projeto vital e ter assim os meios de realizá-lo.

A educação para o desenvolvimento humano precisa considerar todas as dimensões da pessoa e, portanto, também a sua relação com os demais. Nesse sentido, a capacidade de comunicação é essencial para a boa realização da sociabilidade. Por essa razão é que, na primeira seção, deste artigo, se verá qual o sentido da liberdade - eminentemente interior propiciada pela educação e como essa liberdade pode contribuir para que a pessoa seja capaz de realizar seu projeto vital.

O conceito de reabsorção da circunstância, tratado por José Ortega y Gasset, será analisado no contexto da educação em conjunto com a ideia de aceitação preconizada por Victor García Hoz.

Uma consequência da educação é a consciência das próprias limitações, que quando humildemente reconhecida e aceita, faz com que a pessoa se abre para a relação com os demais e o amor ao próximo. Assim, na segunda seção do artigo, o princípio da fraternidade será considerado na educação.

A fraternidade, vista como amizade cívica, promove a consciência e o contato da pessoa com o próximo. A consequência da consideração da fraternidade na educação, como se tratará neste artigo, é o fortalecimento dos laços entre as pessoas e o maior respeito à dignidade humana, com o objetivo final de contribuir para a promoção do bem comum na comunidade política.

Assim, resumidamente, a primeira seção do artigo se ocupará da educação voltada ao desenvolvimento humano a partir do projeto vital. A segunda trará as noções de fraternidade e dignidade humana enquanto meios promocionais da educação. A terceira seção, por fim, relacionará a fraternidade ao bem comum a fim de verificar se o papel da fraternidade na educação pode realizar os contornos de bem comum apresentados no artigo $3^{\circ}$ da Constituição Federal de 1988.

O artigo é concluído pela consideração positiva das limitações humanas que, quando percebidas à luz do princípio da fraternidade, fazem com que de forma concomitante a 
sociabilidade e a personalidade de cada pessoa sejam destacadas a fim de se promover a dignidade humana.

A pesquisa foi desenvolvida utilizando o método de abordagem hipotético-dedutivo, o procedimento comparativo, a técnica de documentação indireta, a pesquisa bibliográfica: em livros e periódicos jurídicos; documental; em legislação e em sites eletrônicos pertinentes.

\section{EDUCAÇÃo, PROJETO VITAL E DESENVOLVIMENTO HUMANO}

A Constituição Federal brasileira de 1988 coloca a educação entre os direitos sociais mencionados em seu artigo $6^{\circ}$. Já no artigo 206, mais especificamente, dispõe que:

A educação, direito de todos e dever do Estado e da família, será promovida e incentivada com a colaboração da sociedade, visando ao pleno desenvolvimento da pessoa, seu preparo para o exercício da cidadania e sua qualificação para o trabalho.

A família, como primeira célula social, é colocada ao lado do Estado como detentora do dever da educação. Vale notar que o primeiro objetivo apontado pelo legislador constitucional para a educação é o pleno desenvolvimento da pessoa, a partir do qual podem ser consideradas as consequências do bom exercício da cidadania e da qualificação para o trabalho, ou seja, a cidadania e o trabalho são algumas (mas não as únicas) emanações do desenvolvimento da pessoa. Buscando uma melhor compreensão do conceito de educação, Jacques Maritain (1968, p. 26) indica três acepções da palavra educação.

\footnotetext{
Tenhamos presente no decorrer desta leitura, que a palavra educação pode ser tomada em três acepções diversas, ainda que se entrelaçando mutuamente com frequência. Num sentido lato, refere-se a todo processo pelo qual um homem se forma e é conduzido à sua realização. No sentido estrito, entende-se a tarefa especial das escolas e universidades; e num terceiro sentido, a obra de formação que os adultos empreendem junto à juventude.
}

Conforme apontou o autor, as três acepções se cruzam porque são complementares: o processo de formação humana - em que consiste a vida propriamente dita - se dá em várias dimensões, especialmente nas universidades, escolas e na formação dos mais jovens levada a cabo pelos que antes deles seguiram o caminho formativo. A educação, portanto, precisa considerar a pessoa e sua natureza. Nesse sentido é que John de Salisbury (2017, p. 269) já no século XII, salientava que "The first task of man aspiring to wisdom is the consideration of what he himself is: what is within him, what without, what below, what above, what opposite, 
what before, and what after"1. Tal afirmação do escolástico inglês pode ser comparada à do filósofo espanhol José Ortega y Gasset (2016, p. 18), do século XX, para quem:

Yo soy yo y mi circunstancia, y si no salvo a ella no me salvo yo. Benefac loco illi quo natus est, leemos en la Biblia. Y en la escuela platónica se nos da como empresa de toda cultura, esta: «salvar las apariencias», los fenómenos. Es decir, buscar el sentido de lo que nos rodea ${ }^{2}$. (Destaques do autor).

A circunstância é parte da pessoa na medida que compõe seu conteúdo autobiográfico, ou seja, permite que a pessoa seja capaz de compreender a própria história e assim atuar para o seu desenvolvimento, isto é, para a sua maturidade (ou ainda: para sua sabedoria, conforme a citação já reproduzida de John de Salisbury). Antes de escrever a conhecida frase replicada na citação anterior, José Ortega y Gasset (2016, p. 17) escreveu que “[...] la reabsorción de la circunstância es el destino del hombre"3. Porque a pessoa não se inventa totalmente, mas amadurece na medida em que considera os elementos concretos de sua vida. O desenvolvimento promovido pela educação deve ser o da reabsorção da circunstância, com todas as dificuldades que isso possa implicar. É neste sentido que Julián Marías afirma:

Y creo que si la palabra educación tiene un sentido, es precisamente este: la mostración de la realidad con sus virtualidades, la participación en ella, la pluralidad de perspectivas, que invierte a la inveterada tendencia a la simplificación y el esquematismo, o el trato apresurado y utilitario con las cosas, resbalando sobre ellas ${ }^{4}$. (MARÍAS, 1993, p. 178-179).

A pluralidade de perspectivas a que se refere Julián Marías vem no sentido de promover um maior contato da pessoa com a realidade em toda a sua complexidade, sem reduções que impeçam a pessoa de ver os problemas e de lidar com eles - tenham ou não uma solução. Por isso é tão necessário relacionar a educação e a maturidade humana. Assim, uma contribuição ímpar é apresentada por Victor García Hoz:

1 Tradução livre: “A primeira tarefa do homem que aspira à sabedoria é a consideração do que ele mesmo é: o que está dentro dele, o que está fora, o que está embaixo, o que está em cima, o que está oposto, o que está antes, e o que está depois."

2 Tradução livre: "Eu sou eu e minha circunstância, e se não a salvo não salvo a mim. Benefac loco illi quo natus est, (Faça o bem ao lugar em que nasceu para ele), lemos na Bíblia. E na escola platônica se nos dá como empresa de toda cultura, esta: 'salvar as aparências', os fenômenos. Isto é, buscar o sentido do que nos rodeia."

3 Tradução livre: “[...] a reabsorção da circunstância é o destino do homem.”

4 Tradução livre: "E creio que se a palavra educação tem um sentido, é precisamente este: a evidenciação da realidade com suas virtualidades, a participação nela, a pluralidade de perspectivas, que inverte a inveterada tendência à simplificação e o esquematismo, ou o trato pressuroso e utilitário com as coisas, resvalando sobre elas." 
A educação personalizada responde ao intento de estimular um sujeito para que aperfeiçoe sua capacidade de dirigir sua própria vida, ou, dito de outro modo, desenvolver sua capacidade de tornar efetiva a liberdade pessoal, participando, com suas características peculiares, da vida comunitária. (HOZ, 2018, p. 34).

A liberdade propiciada pela educação - que conduz ao desenvolvimento descrito na Constituição Federal - não é uma liberdade irrestrita nem muito menos demiúrgica, mas a consequência de uma liberdade interior que torna a pessoa humilde e a ensina a perceber melhor sua própria realidade. A consequência dessa humildade é o contato com o próximo - seja esse próximo outra pessoa ou mesmo o ambiente em que aquele que aos poucos amadurece está inserido. Muitas vezes o impacto dos grandes problemas da vida chama a atenção da pessoa a partir do momento em que ela se dá conta dos problemas mais próximos e imediatos. Por outro lado, "Para quien lo pequeño no es nada, no es grande lo grande"5 (ORTEGA Y GASSET, 2016, p. 17).

A educação promove a liberdade interior tão necessária à consideração do que está ao redor da pessoa, inclusive de suas limitações.

O homem é um ser livre, mas encontra-se rodeado de realidades que nem sempre pode dominar. O mundo material, obediente a leis necessárias, independentes da vontade humana, de fato constitui, em muitas situações, uma limitação à liberdade do homem. Mesmo nessas situações, a liberdade humana tem uma possibilidade de se exercer: aceitar ou não aceitar internamente a situação em que se encontra. De certo modo, a aceitação é também uma escolha; mas, por seu matiz peculiar, creio que valha a pena levá-la em conta e pensar que, na educação da liberdade, deve-se considerar como objetivo fundamental o desenvolvimento da capacidade de escolha, acrescentando, como consequência, o desenvolvimento da capacidade de aceitar ou rechaçar. (HOZ, 2018, p. 47).

O que García Hoz chama de aceitação poderia, a princípio, ser confundido com mera passividade, com uma postura derrotista contrária ao conhecimento e à liberdade preconizados pela educação. No entanto, o conceito de aceitação consiste no exato oposto: a aceitação faz com que o ser humano reabsorva sua circunstância, aceite a si mesmo e conheça os próprios limites para então poder atuar; sua atuação será na conquista da sabedoria, das virtudes, na melhora das condições de vida das demais pessoas etc. A liberdade interior que se segue à aceitação da realidade é o caminho de maturidade que a educação dá à pessoa.

Jacques Maritain, no seu livro que discute profundamente o tema da finalidade da educação como conquista de uma liberdade interior, afirma:

5 Tradução livre: "Para quem o pequeno não é nada, não é grande o grande.” 
As principais aspirações da pessoa são aspirações à liberdade, - não nos referimos aqui ao livre arbítrio, dom da natureza em cada um, mas dessa liberdade que é espontaneidade, expansão ou autonomia que devemos alcançar através de um esforço constante e combate contínuo. E qual a forma mais essencial de uma tal aspiração? É o desejo da liberdade interior e espiritual. Nesse sentido a filosofia grega, Aristóteles em particular, via na independência que o homem adquire pela inteligência e sabedoria, a perfeição do ser humano. E o Evangelho devia elevar a perfeição humana a um nível superior - verdadeiramente divino - afirmando que ela consiste na perfeição do amor e, como diz São Paulo, na liberdade daqueles que são movidos pelo Espírito Divino. [...]. Assim, a primeira finalidade da educação é a conquista da liberdade interior e espiritual pela pessoa individual, ou, em outros termos, a libertação desta através do conhecimento, da sabedoria, da boa vontade e do amor. (MARITAIN, 1968, p. 37-38).

O amor não é um sentimento, mas a expressão da aceitação de que se está a falar neste artigo. Quando o ser humano aceita o seu próximo e a realidade como um todo, passa a amálos - a confirmá-los no ser: "In every conceivable cases love signifies much the same as approval"6 (PIEPER, 1989, p. 28). A educação, portanto, tira a pessoa do egoísmo malsão e faz com que ela levante os seus olhos para aquilo - e aquele - que está fora dela. Esse processo de maturidade é lento e doloroso, mas é o que permite o desenvolvimento autêntico da pessoa e sua realização.

Sem abandonar as lições dos dois autores imediatamente anteriores, Víctor García Hoz faz uma relação importante do viver humanamente enquanto viver com liberdade:

Trata-se de que, através do ensino e por meio da relação pessoal que as atividades orientadoras implicam, o aluno realize o importante e lento aprendizado do viver humano: trabalhar, que é se comunicar com as coisas, e conviver, que é se comunicar com as pessoas. Não se pode viver humanamente a não ser partindo da capacidade de critério próprio para apreciar as pessoas, coisas e situações, escolher o caminho adequado entre várias possibilidades e ater-se às consequências dessa escolha. Viver humanamente é o mesmo que viver com liberdade. E a liberdade implica, recordemolo, capacidade de escolher, mas também capacidade de aceitar a responsabilidade pelos atos livres. (HOZ, 2018, p. 51).

A liberdade interior, é preciso insistir, consiste no conhecimento das próprias limitações e, a partir dele, nos meios imaginados para superar essas limitações. Para que isso seja possível, é necessário que a pessoa possa elaborar imaginativamente seu projeto vital. "A educação personalizada se justifica como estímulo e ajuda a um sujeito para a formulação de seu projeto pessoal de vida e para o desenvolvimento da capacidade de concretizá-lo" (HOZ, 2018, p. 54). Tanto a elaboração quanto a concretização do projeto são eminentemente pessoais: a educação permite que a pessoa tenha os meios adequados para isso, mas cabe à liberdade humana a aceitação ou recusa de sua própria realização.

6 Tradução livre: "Em todos os casos imagináveis o amor significa o mesmo que aprovação." 
É certo que a pessoa desenvolve seu projeto vital graças à expressão que lhe propiciam a educação e a convivência com os demais. A palavra é o meio pelo qual o ser humano consegue expressar o que compreendeu da realidade, o que também tomou para si. Acerca da importância do conceito, Ortega y Gasset (2016, p. 47) afirma que "Solo la visión mediante el concepto es una visión completa; la sensación nos da solo la materia difusa y plasmable de cada objeto; nos da la impresión de las cosas, no las cosas"7. O conceito é propriamente a palavra: ser capaz de comunicar uma experiência - boa ou ruim - permite à pessoa ser mais livre, porque participa melhor de sua experiência e então se abre para ela a escolha de aceitá-la ou não.

\begin{abstract}
No próprio fato de às vezes não podermos expressar adequadamente nossas vivências está oculto um novo valor da educação fundamentada na atividade expressiva. Porque, entendida a expressão em toda a sua amplitude, nela se encontra o signo que pode representar adequadamente a realidade; mas às vezes a realidade não se deixa apreender num signo, e então a própria incapacidade de expressão é um fator da consciência da limitação humana, é uma constante referência não só ao desconhecido, mas à possibilidade do mistério. A insuficiência da linguagem impede o homem de satisfazer-se consigo mesmo. A insatisfação é a origem da tendência permanente pela perfeição pessoal, é o ponto de partida para o progresso humano e é também abertura para uma realidade transcendental superior ao próprio homem. (HOZ, 2018, p. 67).
\end{abstract}

No aparente paradoxo indicado por Víctor García Hoz na citação acima está um dos fundamentos da educação para o desenvolvimento humano: ela não pode ser um mero acúmulo de informações, mas um exercício que a pessoa tem de fazer pela necessidade que lhe é apresentada de comunicar as próprias experiências. A realidade da vida humana aparece então para a pessoa como que a demandar-lhe uma resposta. No entanto, pela complexidade das experiências, nem todas elas podem ser comunicadas. Esse, por exemplo, é o desafio inesgotável encontrado pelos artistas. Ainda assim a tentativa de comunicar imperfeitamente as experiências exige de cada pessoa um esforço de recordação, de aperfeiçoamento e também de humildade.

Finalmente, no se pierda de vista que lo que decimos de los otros se aplica sobre todo a nosotros mismos. Al tomar nuestra medida, al hacer el balance de lo que hemos hecho y podemos hacer, sentimos un grado mayor o menor de estimación; si somos discretos y medianamente inteligentes, nunca será muy alto, porque las deficiencias, ignorancias, tentaciones y flaquezas, aun en los ejemplos más admirables de la especie humana, son considerables ${ }^{8}$. (MARÍAS, 1994, p. 123).

7 Tradução livre: "Só a visão mediante o conceito é uma visão completa; a sensação nos dá só a matéria difusa e modelável de cada objeto; dá-nos a impressão das coisas, não as coisas."

8 Tradução livre: "Finalmente, não se perda de vista que o que dizemos dos outros se aplica sobretudo a nós mesmos. Ao tomar nossa medida, ao fazer o balanço do que fizemos e podemos fazer, sentimos um grau maior ou menor de estimação; se somos discretos e medianamente inteligentes, nunca será muito alto, porque 
O desenvolvimento da pessoa abrange, portanto, também a consciência das próprias limitações. A capacidade expressiva, quando sinceramente buscada, não anula nem exagera tal consciência, mas antes a torna mais clara para a pessoa. A importância dessa consciência e do desenvolvimento humano buscado pela educação se pode notar na relação de cada pessoa com o seu próximo, como se verá na segunda parte deste artigo.

\section{FRATERNIDADE E DIGNIDADE HUMANA ENQUANTO MEIOS PROMOCIONAIS DA EDUCAÇÃO}

A pessoa não está sozinha em sua vida e, pela natureza humana mesma, tal solidão não seria possível. A consideração de uma pessoa abstrata, isolada de comunidades humanas concretas, é na prática algo inimaginável. O momento vivido pela humanidade está demonstrando exatamente isto, ou seja, a necessidade da sociabilidade humana. Grande parte da circunstância de que falou Ortega y Gasset, numa citação já apresentada neste artigo, é composta pela relação da pessoa com o seu próximo. A comunidade humana impõe certos limites a quem a compõe, mas ao mesmo tempo é o meio para seu desenvolvimento e liberdade.

I spoke earlier of the agent as not only an actor, but an author. Now I must emphasize that what the agent is able to do and say intelligibly as an actor is deeply affected by the fact that we are never more (and sometimes less) than the co-authors of our own narratives. Only in phantasy do we live what we please. In life, as both Aristotle and Engels noted, we are always under certain constraints. We enter upon a stage which we did not design and we find ourselves part of an action that was not of our making. Each of us being a main character in his own drama plays subordinate parts in the drama of others, and each drama constrains the others ${ }^{9}$. (MACINTYRE, 2007, p. 213).

O drama mencionado por Alasdair MacIntyre é o projeto vital de todas as pessoas que, pela sociabilidade humana, tem íntima relação com os demais; essa relação pode ser mais próxima ou mais afastada, a depender do contexto, mas não por isso deixa de existir. Os dramas humanos, portanto, mantém contato uns com os outros fazendo com que a pessoa - para se desenvolver - precise ter essa visão ampla de que em sua vida as demais pessoas importam.

as deficiências, ignorâncias, tentações e fraquezas, mesmo nos exemplos mais admiráveis da espécie humana, são consideráveis."

9 Tradução livre: "Eu falei antes do agente não somente como um ator, mas um autor. Agora eu preciso enfatizar que aquilo que o agente é capaz de fazer e dizer inteligivelmente como um ator é profundamente afetado pelo fato de que nunca somos mais (e às vezes menos) do que os coautores de nossas próprias narrativas. Somente na fantasia vivemos o que queremos. Na vida, como tanto Aristóteles quanto Engels notaram, nós estamos sempre sob certas constrições. Nós subimos a um palco que não projetamos e nos encontramos como parte de uma ação que não fizemos. Cada um de nós, sendo personagem principal em seu próprio drama, representa papeis secundários no drama dos outros, e cada drama influencia os demais." 
Se o homem é animal naturalmente político, isto significa que a sociedade, exigida pela natureza, se constitui por livre consentimento e que a pessoa humana reclame comunicações da vida social em razão da abertura e generosidade próprias à inteligência e ao amor, como também das necessidades de um indivíduo que nasce privado de tudo. É assim que a vida social tende a emancipar o homem do jugo da natureza material. Subordina o indivíduo ao bem comum, mas de modo tal que este recai sobre as pessoas individuais e que estas gozam dessa liberdade de expansão ou de independência que são asseguradas pelas garantias econômicas do trabalho e propriedade, direitos políticos, virtudes cívicas e cultura do espírito. (MARITAIN, 1968, p. 42).

Assim se entende que não é possível falar em educação para o desenvolvimento humano sem o cultivo da pessoa em sua relação com os demais e com o bem comum. As relações sociais demandam da pessoa uma maturidade tal que, para o seu pleno desenvolvimento, não se pode esquecer da comunidade concreta em que vive e na qual atua. Apesar dessa necessidade, vale ainda enfatizar que tal sociabilidade que a educação propicia não se pode confundir com o coletivismo.

É, pois, evidente que a educação do homem deve preocupar-se com o grupo social e preparar a criança para desempenhar nele seu papel. Formar o homem para uma vida normal, útil e devotada na comunidade, ou orientar o desenvolvimento da pessoa humana na esfera social, despertando e fortificando o senso de sua liberdade como o de suas obrigações e responsabilidades, constitui o objetivo essencial da educação. Mas esse não é o fim último, é o segundo de seus fins essenciais. O fim último da educação refere-se à pessoa humana na sua vida pessoal e progresso espiritual, não nas suas relações com o meio social. Tratando-se da finalidade secundária de que estamos falando, não devemos jamais esquecer que a própria liberdade pessoal está no centro da vida social, e que uma sociedade humana é, na verdade, um agrupamento de liberdades humanas que se submetem à obediência, ao sacrifício e a uma lei comum em benefício do bem comum, de modo a tornar essas liberdades pessoais capazes de atingir, em cada um, a plena e verdadeira realização humana. (MARITAIN, 1968, p. 42-43).

Tal citação de Maritain pode parecer, de início, contradizer o seu próprio conceito de sociabilidade humana e fazê-lo cair na mesma posição contratualista, segundo a qual os indivíduos abdicam de parte de sua liberdade em prol da comunidade política em troca de proteção e benefícios. No entanto, a aparente contradição não resiste a um exame mais profundo: a renúncia e as constrições impostas às pessoas pelas leis da comunidade política em que estão inseridas não fazem necessariamente com que sua liberdade seja tolhida, mas antes constituem instrumentos aptos a realizar o pleno desenvolvimento humano. As limitações auxiliam cada pessoa, educada na liberdade da aceitação, a considerar o próximo como a um igual e buscar o seu desenvolvimento com o apoio dos demais. A educação para a liberdade humana, portanto, procura respeitar a pessoa em sua relação de proximidade com os demais. 
$\mathrm{E}$, agindo de acordo com a lei, o bom cidadão há de se acostumar com isso e, por meio do hábito decorrente da reiterada prática de atos virtuosos por força da lei, pode vir a se tornar também um bom homem, praticando tais atos não mais por força da lei, mas por vontade própria. Então a lei humana, além de regular as minúcias das relações entre os homens, serve também para lhes impor disciplina. (CACHICHI, 2019, p. 142).

A palavra disciplina soa como constrição; tem um sentido negativo quando se pensa num conceito de liberdade que compreende a mera satisfação de impulsos. No entanto, a disciplina é um instrumento para a liberdade na medida em que permite com que a pessoa conquiste a virtude, ou seja, o hábito. E qualquer hábito só pode ser conquistado quando a vontade livremente aceita a disciplina. Nesse sentido, a educação para o desenvolvimento humano pleno - a pessoa enquanto tal e também inserida numa comunidade política - não somente impõe uma disciplina, mas procura ensinar a razão da existência de cada disciplina para que a pessoa possa escolher acatá-la.

A educação é também uma educação para o bem comum, como bem afirma Lafayette Pozzoli:

\begin{abstract}
Vale a pena ressaltar dos escritos de Maritain, que o bem comum de determinado grupo humano, é uma comunhão no bem-viver. Comum ao todo e às partes, sob pena de ir contra a própria natureza, o bem comum exige o reconhecimento dos direitos fundamentais das pessoas, e detém como o valor principal a maior possibilidade de acesso das pessoas à liberdade intrínseca de cada um de se expandir e evoluir, bem como às manifestações do bem que por sua vez daí prossegue e se comunica. (POZZOLI, 2001, p. 88).
\end{abstract}

De modo que o bem comum não tolhe cada pessoa que forma a comunidade, mas antes é uma das condições para o seu pleno desenvolvimento. A liberdade intrínseca à natureza humana e sua necessidade de manter relações com os demais encontram no bem comum o aperfeiçoamento de que precisam para sua realização. O laço que une as pessoas na comunidade, portanto, deve estar pautado antes na amizade cívica do que no coletivismo ou no individualismo.

As experiências históricas de realização de igualdade à custa da liberdade (totalitarismo) ou do sacrifício da igualdade (de oportunidades, inclusive) em nome da liberdade (sentido especialmente econômico: mercado) revelam o desastre de uma tentativa de transformação social não alicerçada na fraternidade. (FONSECA, 2018, p. 166). 
Pois fraternidade é o nome dessa amizade cívica capaz de unir as pessoas não para tolher cada personalidade específica, mas para promover o desenvolvimento demandado pela própria natureza social do ser humano.

A fraternidade, por mais que esteja em nossas culturas, sua relação com a religião, aqui, fica claramente apresentada como o grande objetivo da organização jurídica. A ordem jurídica, fundada no princípio da igualdade e da paz, voltada para a dignidade da pessoa humana, é o ordenamento da fraternidade. O ser humano não deve ser visto apenas como um ser que existe, mas deve ser visto essencialmente como um ser que vive em sociedade. (POZZOLI; MUNHOZ; SIQUEIRA, 2019, p. 185).

Seguindo a linha dos autores acima citados, a sociedade não é extrínseca ao ser humano, mas parte de sua natureza mesma e assim absolutamente necessária ao seu desenvolvimento. A educação que não promove a integração da pessoa com os demais (desde a família até às instituições da comunidade política, passando pela comunidade imediata) falha em atingir o objetivo do desenvolvimento humano. A percepção da fraternidade, tanto na ordem jurídica quanto na ordem pessoal, permite a integração de que a pessoa precisa.

Insistimos sobre o fato de que a educação deve ser orientada para o desenvolvimento e a libertação da pessoa individual. O que criticamos é essa forma errônea de apreciação da pessoa individual que, tendo em vista a individualidade, em lugar da personalidade, reduz a educação ao progresso do homem à simples libertação do ego material. Os educadores que caem nesse erro acreditam dar ao homem a liberdade de expansão e de autonomia à qual aspira a pessoa, enquanto ao mesmo tempo, negam o valor de toda disciplina e de toda ascese, assim como a necessidade de esforçar-se para a perfeição pessoal. Como consequência, em lugar de realizar-se, o homem se dispersa e se desintegra. (MARITAIN, 1968, p. 69, destaque do autor).

Uma vez compreendida a fraternidade nas ordens educacional e jurídica - que são complementares e foram aqui divididas somente para efeitos didáticos - pode-se perceber que esse princípio é eminentemente integrador e, quando considerado na educação da pessoa, contribui para o seu desenvolvimento; não a dissolve na coletividade, mas a impele a participar ativamente em sua comunidade para melhor realizar a própria personalidade. O princípio da fraternidade pode ser aplicado considerando as seguintes características:

(i) compreensão da fraternidade como experiência possível, (ii) o estudo e a interpretação da história a luz da fraternidade, (iii) a colaboração entre teoria e prática da fraternidade na esfera pública, (iv) a interdisciplinaridade dos estudos e (v) o diálogo entre culturas. (FONSECA, 2019, p. 54).

A partir dessas características metodológicas advindas do princípio da fraternidade podem ser apontados alguns elementos importantes relacionados à educação e ao 
desenvolvimento da pessoa. Este artigo se ocupa de um deles: a dignidade humana, corolário da educação para o desenvolvimento e manifestação de uma concepção educacional que considera a pessoa no seu centro.

Tendo como referência a dignidade do ser humano é fácil identificar seu critério subjetivo, já que cada ser humano possui sua própria dignidade, não perante o Estado, mas perante sua sociedade, o que assim, passa a ter, a dignidade humana, valor em 'pé de igualdade' à vida do homem, vez que, um não tem sentido sem o outro. (POZZOLI; TOLEDO, 2017, p. 181).

A dignidade humana é exaltada - no bom sentido da palavra - quando a educação está voltada para o desenvolvimento da pessoa em todas as suas dimensões: física, social e espiritual. Somente na consideração da fraternidade como amizade cívica e contato com o próximo é que a dignidade humana pode chegar ao heroico extremo do sacrifício pelo outro.

Precisamente en esta relativización del propio yo finito, de los propios deseos, intereses y objetivos, se dilata la persona y se hace algo absoluto. Se hace inconmensurable. Puede ponerse a sí mismo en servicio de algo distinto de sí, hasta el sacrificio de sí mismo. Es capaz del amor Dei usque ad contemptum sui, por decirlo con Agustín. Y precisamente sobre la base de esta posibilidad, la persona - no como ser natural, sino como ser potencialmente moral - se convierte en un fin absoluto. Debido a que puede relativizar sus propios intereses, puede pretender que se respete su status absoluto de sujeto. Debido a que puede asumir libremente obligaciones, nadie tiene el derecho de hacerle esclavo, pues - como vio Kant correctamente - no puede tener ninguna obligación frente a su señor. Porque el hombre es, como ser moral, una representación de lo absoluto, por eso y sólo por eso, le corresponde aquello que llamamos 'dignidad humana' ${ }^{10}$. (SPAEMANN, 1988, p. 22-23, destaques do autor).

Vale aqui uma lembrança da lição maritainiana que consistiu em afirmar a verdade na liberdade, tendo a dignidade da pessoa humana como suporte maior. Uma justificação racional dos direitos humanos só é possível, segundo Maritain, pela descoberta da lei natural, entendida nas suas conotações realmente metafísicas e no seu dinamismo realista, isto é, uma noção de lei natural conotada simultaneamente com a natureza e com a experiência. Por outro lado, é

10 Tradução livre: "Precisamente nesta relativização do próprio eu finito, dos próprios desejos, interesses e objetivos, a pessoa se dilata e se faz algo absoluto. Faz-se incomensurável. Pode por a si mesma a serviço de algo distinto de si, até o sacrifício de si mesma. É capaz do amor Dei usque ad contemptum sui, por dizê-lo com Agostinho. E precisamente sobre a base desta possibilidade, a pessoa - não como ser natural, mas como ser potencialmente moral - se torna um fim absoluto. Devido a que pode relativizar seus próprios interesses, pode pretender que se respeite seu status absoluto de sujeito. Devido a que pode assumir livremente obrigações, ninguém tem o direito de fazê-la escrava, pois - como viu Kant corretamente - não pode ter nenhuma obrigação frente a seu senhor. Porque o homem é, como ser moral, uma representação do absoluto, por isso e só por isso, lhe corresponde aquilo que chamamos 'dignidade humana'”. 
necessário considerar o ser humano enquanto pessoa: aqueles direitos são direitos da pessoa humana.

Por fim, percebe-se a dignidade humana enquanto centro da educação voltada para a pessoa e, ao mesmo tempo, como realização do amor ao próximo que só o ser humano é capaz de ter desde que se esforce dentro dos limites do próprio projeto vital. A fraternidade, nesse sentido, é um dos meios de se exercitar o amor ao próximo na comunidade política e promover o bem comum, conforme se verá na seção seguinte deste artigo.

\section{Fraternidade E BEM COMUM: O DESENVOlvimento dA PESSOA NA COMUNIDADE POLÍTICA}

Uma vez citada, logo no início, a presença da educação na Constituição Federal brasileira, este artigo tomou uma deriva personalista e procurou se ocupar do desenvolvimento da pessoa justamente no sentido de se adequar ao que dispõe o texto constitucional. Em seguida, ainda à luz personalista de Maritain, Julián Marías e Víctor García Hoz, a fraternidade foi trazida enquanto elemento promocional da pessoa em sua relação com as demais na comunidade política. Pode-se então falar, ao mesmo tempo, de uma educação para a fraternidade e da fraternidade na educação. A consequência de tal relação é cultivar um terreno fértil para o bem comum, cujos contornos podem ser percebidos quando se lê o artigo $3^{\circ}$ da Constituição Federal de 1988:

\footnotetext{
Art. $3^{\circ}$ Constituem objetivos fundamentais da República Federativa do Brasil:

I - construir uma sociedade livre, justa e solidária;

II - garantir o desenvolvimento nacional;

III - erradicar a pobreza e a marginalização e reduzir as desigualdades sociais e regionais;

IV - promover o bem de todos, sem preconceitos de origem, raça, sexo, cor, idade e quaisquer outras formas de discriminação.
}

Conforme foi dito - ainda que de passagem - na seção anterior, o bem comum não consiste na mera soma de bens individuais (pequenas satisfações), mas na integração da comunidade reunida em torno de um auxílio mútuo voltado ao desenvolvimento material e moral (POZZOLI, 2001, p. 87). Os contornos desse bem, que é de realização de todas as pessoas (por isso, comum) estão delineados nos quatro incisos do artigo $3^{\circ}$ da Constituição brasileira. Poder-se-ia ler o texto com ainda mais cuidado e então a conclusão seria a de que os três últimos 
incisos decorrem do primeiro, posto que uma sociedade livre, justa e solidária não comportaria desigualdades, o bem de apenas uma parcela da população nem o impedimento ao desenvolvimento nacional (que, por sua vez, deve ser entendido enquanto bem das pessoas que compõem a nação). Para construir uma sociedade que seja livre, justa e solidária - que atente, portanto, ao bem comum - a educação tem um papel de suma importância.

A educação é uma sabedoria prática que visa à formação da pessoa e tende a torná-la mais livre, conduzi-la à sua plenitude pessoal e social e, consequentemente, à vida democrática/participativa. [...]. O produto da educação deve ser a pessoa humana que existe e que existe de boa vontade, por se sentir respeitada em sua personalidade, considerar-se como parte da comunidade humana e poder expressar sua vontade e tendência ao bem. (POZZOLI, 2001, p. 60, destaque do autor).

Aqui é necessário tornar à noção de projeto vital, desenvolvida na primeira seção do artigo: o projeto vital consiste num plano razoável de vida traçado pela pessoa para a sua realização no seio da comunidade política (que será, propriamente, sua relação pessoal, posto que não exclui nenhuma de suas conquistas individuais). A educação e o próprio desenvolvimento da pessoa dependem de sua relação com a comunidade; mais concretamente, com as demais pessoas. Essa relação não se resume a mera observância de requisitos normativos; mas, uma vez que os requisitos normativos reconhecem (e não necessariamente criam) que o desenvolvimento humano se dá em comunidade, cabe a cada pessoa fortalecer os seus laços com a comunidade por meio da amizade cívica. Conforme explicou Luis Fernando Barzotto (2010, p. 151), a lei enquanto medida e ordem não é suficiente para esgotar a experiência da lei.

O ser humano exige ser reconhecido como pessoa, e por isso, a mediação social da lei deve incorporar uma relação de amizade. A medida exposta na lei e a ordem por ela imposta devem respeitar o caráter de pessoa do ser humano, e isso só ocorre se a amizade é o sentido da lei. Pode-se propor como fórmula da aliança que existe entre os seres humanos e que deve se expressar na lei, a regra de ouro: 'Faze ao outro o que queres que façam a ti'. (BARZOTTO, 2010, p. 151).

Barzotto aponta em direção a uma demanda que é intrinsecamente humana: o reconhecimento como pessoa. Pode-se pensar, num primeiro momento, que tal reconhecimento é demandado do Estado - e esse pensamento está correto. Mas é necessário ir um pouco adiante: além de reconhecimento por parte do Estado, é imprescindível que cada ser humano veja no outro uma pessoa, alguém cujo desenvolvimento importa ao bem comum. Há então uma obrigação mútua entre todos os seres humanos. 
Toda pessoa torna-se um sujeito de dever (próximo/co-humano) face a toda pessoa humana. Viver em comunidade é viver em débito com relação aos outros membros, aproximando-se para realizar o que lhes é devido. A reciprocidade abarca todo o humano. (BARZOTTO, 2010, p. 59).

O papel da fraternidade é precisamente o de avivar esse reconhecimento que resulta na consciência do dever de obrigação mútua entre as pessoas e, consequentemente, na garantia dos direitos humanos enquanto meios de realização de cada pessoa. O bem comum é consubstanciado nos direitos humanos, reconhecidos e garantidos - mas não criados - pela autoridade estatal que, por sua vez, encontra neles o seu fundamento.

Uma educação que esteja voltada para a pessoa enquanto membro da comunidade, ou seja, enquanto um ser aberto que precisa dos demais para a sua própria realização ao mesmo tempo que tem para com eles alguns deveres, fomenta a noção de bem comum como necessário ao desenvolvimento. Pode-se dizer que a fraternidade está no início da educação - ao enfatizar essa abertura do ser humano - e também no seu fim - na consequência de um projeto vital pensado e voltado para o bem comum, de modo a contribuir inclusive com aquilo que está disposto na Constituição Federal de 1988.

\section{CONSIDERAÇÕES FINAIS}

Este artigo procurou mostrar como a educação para o pleno desenvolvimento da pessoa atinge seu fim quando a pessoa é considerada em todas as suas dimensões: física, social e espiritual. Para que tal consideração - que deve partir dos educadores e dos educandos - seja possível, é necessário que se compreendam as possibilidades de cada vida humana e suas limitações.

As limitações são, na verdade, meios que a pessoa tem de conseguir se realizar, desde que as aceite livremente. Por essa razão foi que Ortega y Gasset, como já visto, considerou de suma importância a reabsorção da circunstância pela pessoa.

O mesmo filósofo espanhol tratou ainda acerca da capacidade de expressão - a elaboração do conceito - das experiências como necessárias para a boa vida humana. Assim se pôde ver que a educação para a comunicação, o aprendizado de novos meios de expressão, dota a pessoa de maior capacidade e liberdade. A sociabilidade da natureza humana demanda a comunicação compreensiva para com as demais pessoas.

Nesse sentido a fraternidade, enquanto amizade cívica, auxilia na promoção da educação para o pleno desenvolvimento da dignidade da pessoa. Por meio da fraternidade a personalidade 
individual não é tolhida, mas considerada totalmente. Ademais, a fraternidade permite que se compreenda a dignidade humana que, por sua vez, deve levar ao amor ao próximo.

A consequência da fraternidade entendida como presente no começo e no fim da educação é a promoção do bem comum na comunidade política. Entende-se que a Constituição Federal de 1988 delineou contornos de bem comum, dentre os quais está o artigo $3^{\circ}$, citado nesta pesquisa. A fraternidade tem um papel importante por proporcionar a abertura do ser humano aos demais - para a realização do bem comum - ao mesmo tempo que o lembra dos seus deveres de reconhecimento para com o próximo.

\section{REFERÊNCIAS BIBLIOGRÁFICAS}

BARZOTTO, Luis Fernando. Filosofia do Direito: Os Conceitos Fundamentais e a Tradição Jusnaturalista. Porto Alegre: Livraria do Advogado, 2010.

BRASIL. Constituição da República Federativa do Brasil, de 5 de outubro de 1988. Brasília: Presidência da República, 1988. Disponível em:

http://www.planalto.gov.br/ccivil_03/constituicao/constituicao.htm. Acesso em: 30 abr. 2021.

CACHICHI, Rogério Cangussu Dantas. Lex e iustitia em Santo Tomás. In: BANNWART JÚNIOR, Clodomiro José; FUGA, Bruno Augusto Sampaio (Orgs.). Filosofia do direito.

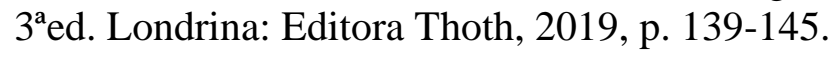

FONSECA, Reynaldo Soares da. O princípio constitucional da fraternidade: seu resgate no sistema de justiça. Belo Horizonte: Editora D’Plácido, 2019.

FONSECA, Reynaldo Soares da. O princípio jurídico da fraternidade na jurisprudência do STF e do STJ. In: MACHADO, Carlos Augusto Alcântara; JABORANDY, Clara Cardoso Machado; BARZOTTO, Luciane Cardoso (orgs.). Direito e fraternidade: em busca de concretização. Sergipe: Edunit, 2018, p. 159-204.

HOZ, Víctor García. Educação Personalizada. Tradução de Felipe Denardi. Campinas: Kírion, 2018.

LÓPEZ, Edgardo Torres; POZZOLI, Lafayette; MONTEMOR, Silmara Veiga (Orgs.). Humanismo e Fraternidade Direito Ambiental. Curitiba, Instituto Memória, 2020.

MACINTYRE, Alasdair. After Virtue: A Study in Moral Theory. $3^{\text {a }}$ ed. Indiana: University of Notre Dame Press, 2007.

MARÍAS, Julián. La Educación Sentimental. Barcelona: Círculo de Lectores, 1993.

MARÍAS, Julián. Mapa del Mundo Personal. Madrid: Alianza Editorial, 1994.

MARITAIN, Jacques. Rumos da Educação. $5^{\text {a }}$ ed. Tradução da Abadia de Nossa Senhora das Graças. Rio de Janeiro: Agir, 1968. 
ORTEGA Y GASSET, José. Meditaciones del Quijote. Campinas: Livre, 2016.

PIEPER, Josef. An Anthology. San Francisco: Ignatius Press, 1989.

POZZOLI, Lafayette. Maritain e o Direito. São Paulo: Loyola, 2001.

POZZOLI, Lafayette; MUNHOZ, Cátia Martins da Conceição; SIQUEIRA, Gilmar. Dignidade da Pessoa Humana e Direito Fraterno -Percurso do Direito como Função Promocional. In: GUNTHER, L., E.; FISCHER, O., C. (coords.); LEAHY, É.; CACHICHI, R., C., D. (orgs.). Constitucionalismo e direitos fundamentais. Curitiba: Instituto Memória, 2019, p.179-193.

SALISBURY, John. Policraticus. In: GAMBLE, Richard M. (ed.). The Great Tradition: Classic Readings on what it means to be an Educated Human Being. Wilmington: ISI Books, 2017, p. 268-280.

SANTOS, Ivanaldo; POZZOLI, Lafayette (Org.). Direito e educação. fraternidade em ação: uma abordagem interdisciplinar. $1^{a}$ ed. São Paulo: Letras Jurídicas, 2014.

SPAEMANN, Robert. Sobre el Concepto de la Dignidad Humana. Revista Persona y Derecho, Navarra, n.19, 1988.

TOLEDO, Iara Rodrigues; POZZOLI, Lafayette. Análise do princípio constitucional da dignidade humana face a dimensão da afetividade e o direito fraternal. In: Problemata. Revista Internacional de Filosofia, v. 8, p. 178-190, 2017. DOI: https://doi.org/10.7443/problemata.v8i1.27851. 